\title{
Pyrazoline Stereochemistry: Use of Nuclear Magnetic Resonance Shift Reagents with Azo-compounds
}

\author{
By Stephen R. Wilson* and (the late) Richard B. Turner \\ (Department of Chemistry, California Institute of Technology, Pasadena, California 91106)
}

Summary $\mathrm{Eu}(\mathrm{fod})_{3}$ shifts the n.m.r. spectra of cis-azocompounds, whereas trans-azo-compounds remain almost unaffected; shifts obtained from pyrazolines have been related to their stereochemistry.

WE report the results of a study on the effect of the shift reagent $\mathrm{Eu}(\mathrm{fod})_{3}$ on azo-compounds. Although the use of such n.m.r. shift reagents is commonplace, only passing reference has been made to their use with pyrazolines $^{\mathbf{1}}$ and several reports have appeared claiming azo-compounds do not complex..$^{2,3}$ In the course of a synthesis of the sesquiterpene marasmic acid, ${ }^{4}$ we determined the stereochemistry of pyrazoline intermediates. In order to determine the effect of $\mathrm{Eu}(\mathrm{fod})_{3}$ on azo-compounds, a study of transazobenzene (1), cis-azobenzene (2), azo-2-methylpropane (3), and 1,4-dimethyl-2,3-diazabicyclo[2,2,2]oct-2-ene (4) was 
undertaken. We found that the cis-azo-compounds (2) and (4) complex strongly with the reagent, whereas the transazo-compounds (1) and (3) remain virtually unaffected. The n.m.r. spectrum of the cis-azobenzene (2), for example, shows the ortho-protons shifting to a multiplet at $\delta \mathbf{1 3} \cdot 2$ with one equivalent of $\mathrm{Eu}(\mathrm{fod})_{3}$. When three pyrazoline intermediates were studied, the lines for the shifts of the methylene $\mathrm{AB}$ quartet adjacent to the azo-linkage possess identical slopes and the greatest shifts. Equivalent environments of the azo-linkage in the three compounds can be inferred by the similarly identical slopes of other corresponding protons. The cis-azo-linkage complexes less strongly than $\mathrm{OH}$ but more strongly than $\mathrm{CO}$ or $\mathrm{CO}_{2} \mathrm{Me}$.

We thank the Robert A. Welch Foundation, Houston, Texas, for support of this work, and Dr. Paul Engel, Rice University, Houston, Texas, for gifts of compounds (3) and (4).

(Received, 30th April 1973; Com. 616.)

1 R. G. Bergman and R. A. Keppel, J. Amer. Chem. Soc., 1972, 94, 1350.

2 C. Beate, Z. W. Wolkowski, and N. Thoai, Chem. Comm., 1971, 700.

${ }^{3}$ R. E. Rondeau, M. A. Berwick, R. N. Steppel, and M. P. Serve, J. Amer. Chem. Soc., 1972, 94, 1096, footnote 16.

4 S. R. Wilson and R. B. Turner, J. Org. Chem., in the press. 